\title{
PEMBELAJARAN PHOTOSHOP MENGGUNAKAN METODE WEB PRODUCT BASED LEARNING PADA GLOBAL SCIENCE INSTITUTE (GSI) TERNATE
}

\section{PHOTOSHOP LEARNING USING WEB PRODUCT BASED LEARNING METHODS IN GLOBAL SCIENCE INSTITUTE (GSI) TERNATE}

\author{
Darman Umagapi \\ Program Studi Teknik Komputer, \\ Politeknik Sains dan Teknologi Wiratama Maluku Utara \\ Umagapie01@yahoo.com
}

\begin{abstract}
Abstrak
Penelitian ini bertujuan untuk: (1) Mengembangkan media pembelajaran berbasis website pada mata pelajaran Photoshop. (2) Mengetahui tingkat kelayakan media pembelajaran berbasis website pada mata pelajaran Photoshop. (3) Mengetahui efektivitas media pembelajaran berbasis website yang dikembangkan untuk pembelajaran Photoshop. Tugas seorang instruktur adalah mengarahkan peserta didik berkembang menjadi manusia yang berkualitas sehingga mampu dan proaktif menjawab tantangan zaman yang selalu berubah. Pelaksanaan pembelajaran Photoshop membutuhkan ketrampilan infrastruktur dalam mengimplementasikan strategi pembelajaran agar mampu menjembatani siswa untuk meningkatkan kualitas proses dan hasil belajar untuk mencapai tujuan pembelajaran Photoshop tersebut. Metode yang digunakan dalam penelitian ini adalah penelitian pengembangan (Research and Development). Hasil penelitian ini adalah tahap perencanaan, desain dan pengembangan. Sistem pengujian yang dilakukan terhadap kelayakan produk website sebagai media pembelajaran meliputi uji kerja siswa melalui hasil desain yang sudah di buat oleh siswa. Diharapkan Agar mempermudah pihak Lembaga terutama seorang instruktur dalam proses belajar mengajar dengan menyajikan video Tutorial yang ada pada website dengan menggunakan Web product Based Learning
\end{abstract}

\section{Kata Kunci: Pembelajaran, Photoshop dan Web Product Based}

\begin{abstract}
This study aims to: (1) Develop website based learning media on Photoshop subjects. (2) Knowing the feasibility level of the website based learning media on Photoshop subjects. (3) Knowing the effectiveness of website-based learning media developed for Photoshop learning. An instructor's task is to educate learners to become qualified human beings capable and proactive in responding to ever-changing challenges. The implementation of Photoshop learning requires instructional skills in implementing learning strategies in order to bridge the students to improve the quality of the process and learning outcomes to achieve the purpose of learning Photoshop. The method used in this research is research development (Research and Development). The results of this study are planning, design and development. Testing system conducted on the feasibility of website product as learning media includes student work test through design result which has been made by the student. Expected To facilitate the Institution is primarily an instructor in the learning process by presenting video Tutorials on the website by using the Web product Based Learning
\end{abstract}

Keyword: Learning, Photoshop, Web Product Based 


\section{PENDAHULUAN}

Seiring dengan kemajuan di bidang teknologi informasi dan komunikasi, maka dunia pendidikan juga telah banyak yang memanfaatkan web sebagai media pembelajaran. Meskipun banyak penelitian menunjukan bahwa efektifitas pembelajaran menggunakan internet (elearning) cenderung sama bila dibanding dengan pembelajaran konvensional atau klasikal, tetapi keuntungan yang bisa diperoleh adalah dalam hal fleksibilitasnya (Herman Dwi Surjono, 2008: 1).

Mengembangkan pembelajaran berbasis web yang efektif, memerlukan penerapan suatu pendekatan system dan prinsip-prinsip desain pembelajaran. Pendekatan system memberikan suatu kerangka kerja atau panduan pada kita sebagai seorang pengembang untuk mendesain materi pembelajaran. Guna mendapatkan desain pembelajaran efektif, pengembang harus berpegang pada prinsipprinsip desain pembelajaran, sehingga materi pembelajaran yang dikembangkan memang berorientasi kepada siswa atau peserta didik dan akan meningkatkan efektivitas materi yang disajikan.

Bagi para pengajar, internet bermanfaat dalam mengembangkan profesinya, karena dengan internet dapat: (a) meningkatkan pengetahuan, (b) berbagi sumber diantara rekan sejawat, (c) bekerjasama dengan pengajar di luar negeri, (d) kesempatan mempublikasikan informasi secara langsung, (e) mengatur komunikasi secara teratur, dan (f) berpartisipasi dalam forum-forum lokal maupun internasional (Rechdalle: 2005). Para pengajar juga dapat memanfaatkan internet sebagai sumber bahan mengajar dengan mengakses rencana pembelajaran atau silabus online dengan metodologi baru, mengakses materi pelajaran yang cocok untuk siswanya, serta dapat menyampaikan ide-idenya. Sedangkan peserta didik juga dapat menggunakan internet untuk belajar sendiri secara cepat, sehingga akan meningkatkan dan memperluas pengetahuan, belajar berinteraksi, dan mengembangkan kemampuannya.

\section{Rumusan Masalah}

Berdasarkan uraian latar belakang sebelumnya maka dirumuskan masalah bagaimana membuat pembelajaran Photoshop menggunakan metode Web Product Based Learning Pada Global Science Institute (GSI) Ternate, Agar mempermudah pihak Lembaga terutama seorang instruktur dalam proses belajar mengajar dengan menyajikan video Tutorial yang ada pada website dengan menggunakan Web product Based Learning

\section{Tinjauan Pustaka \\ Defenisi Sistem Informasi}

Menurut Hartono (2013:16) Sistem informasi adalah seperangkat komponen yang saling berhubungan, yang bekerja untuk mengumpulkan dan menyimpan data serta mengolahnya menjadi informasi untuk digunakan. Burch dan Strater (2005:15) Kumpun bagian-bagian yang formal dan sistematis yang melaksanakan operasi pengolahan data untuk (a) memenuhi persyartan pengolahan data yang legal dan transaksional, (b) memberikan informasi kepada manajemen untuk mendukung kegiyatan - kegiatan perencanaan, pengendalian, dan pengambilan keputusan, dan (c) memberikan bermacam-macam laporan seperti yang diperlukan oleh pihakpihak luar.

\section{Pengertian HTML}

Hypertext Markup Language (HTML) adalah bahasa standard yang digunakan 
untuk menampilkan halaman web (Hidayatulla dan Kawistara, 2014:13). Yang bisa dilakukan dengan HTML yaitu:

1. Mengatur tampilan dari halaman web dan isinya.

2. Membuat tabel dalam halaman web.

3. Mempublikasikan halaman web secara online

4. Membuat form yang bisa di gunakan untuk menangani registrasi dan transaksi via web.

5. Menambahkan objek-objek seperti citra, audio, video, animasi, java applet dalam halaman web.

6. Menampilkan area gambar (canvas) di browser.

\section{Pengertian Web Server}

Menurut Oktavian (2013:14) "Web

Server adalah aplikasi yang berguna untuk menerima permintaan informasi dari pengguna melalui web browser, dan mengirimkan permintaan kembali informasi yang diminta melalui HTTP (HyperText Transfer Protocol). Biasanya Web Server diletakkan dikomputer tertentu pada web hosting".

\section{Pengertian MySQL}

Menurut Agus Saputra (2011:69) secara umum database berfungsi sebagai tempat atau wadah untuk menyimpan, mengklasifikasikan data secara profesional. MySQL bekerja menggunakan SQL Language (Structure Query Language). Itu dapat diartikan bahwa MySQL merupakan standar penggunaan database di dunia untuk pengolahan data.

\section{Pengertian PHP}

Menurut Sibero (2011: 49) PHP Pemrograman interpreter yaitu proses penerjemahan baris kode sumber menjadi kode mesin yang dimengerti komputer secara langsung pada saat baris kode dijalankan.

\section{Pengertian Photoshop}

Adobe Photoshop CS (Creative Suit) dalah versi terbaru dari program pengolah gambar Adobe Photoshop. Adobe Photoshop telah lama kita kenal sebagai program pengolah gambar paling terkemuka di pasaran. Yang digunakan mulai dari desainer grafis, kalangan periklanan, fotografer dan sebagainya. Hal tersebut disebabkan bahwa Adobe Photoshop telah menjadi standar dalam dunia desain grafis.

CREATIVE Suite ( CS ) menawarkan keunggulan berbagai fasilitas baru dibandingkan dengan versi sebelumnya, hal ini akan menguntungkan dan memudahkan pengguna dalam penggunaan program ini untuk melakukan pekerjaan dalam dunia desain grafis.

\section{Pengertian MySQL}

Raharjo (2011:21) mengatakan, MySQL merupakan software RDBMS (atau software database) yang dapat mengelola database dengan sangat cepat, dapat menampung data dalam jumlah sangat besar, dapat diakses oleh banyak user (multi-user), dan dapat melakukan suatu proses secara sinkron atau berbarengan (multi-treaded).

\section{Pengertian Basis Data}

Menurut Anhar (2010: 45) Database adalah sekumpulan tabel-tabel yang berisi data dan merupakan kumpulan dari field atau kolom. Struktur file yang menyusun sebuah database adalah Data Record dan Field.

\section{METODE PENELITIAN Jenis dan Sumber Data}


Jenis data yang dilakukan oleh peneliti adalah data sekunder dimana data tersebut didapatkan dari hasil pengambilan dokumen. Sedangkan untuk sumber data sendiri peneliti khususkan tempat dimana peneliti jadikan objek penelitian yaitu pada Global Science Institute (GSI) Ternate.

\section{Metode Pengembangan Sistem}

Penelitian ini menggunakan pendekatan Research and Development (R\&D). Menurut Sugiyono (2009:407) metode penelitian Research and Development yang selanjutnya akan disingkat menjadi R\&D adalah metode penelitian yang digunakan untuk menghasilkan produk tertentu, dan menguji keefektifan produk tersebut. Produk tersebut tidak selalu berbentuk benda atau perangkat keras (hardware), seperti buku, alat tulis, dan alat pembelajaran lainnya. Akan tetapi, dapat pula dalam bentuk perangkat lunak (software).

\section{Analisa sistem yang berjalan}

Sistem yang berjalan adalah sistem awal yang digunakan yang masih manual dalam pengerjaannya, berkut adalah flowchart sistem yang berjalan

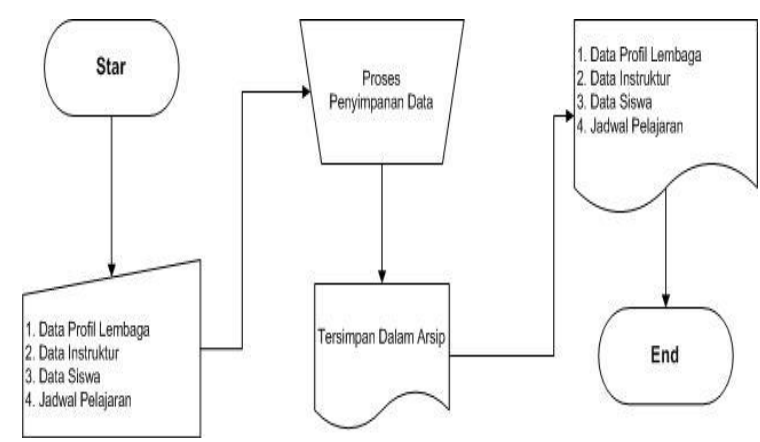

Gambar 1. Flowchart Sistem Yang Berjalan

\section{Rancangan system yang di usulkan}

Sistem yang diusulkan adalah usulan sistem baru, berikut flowchart rancangan sistem yang diusulkan

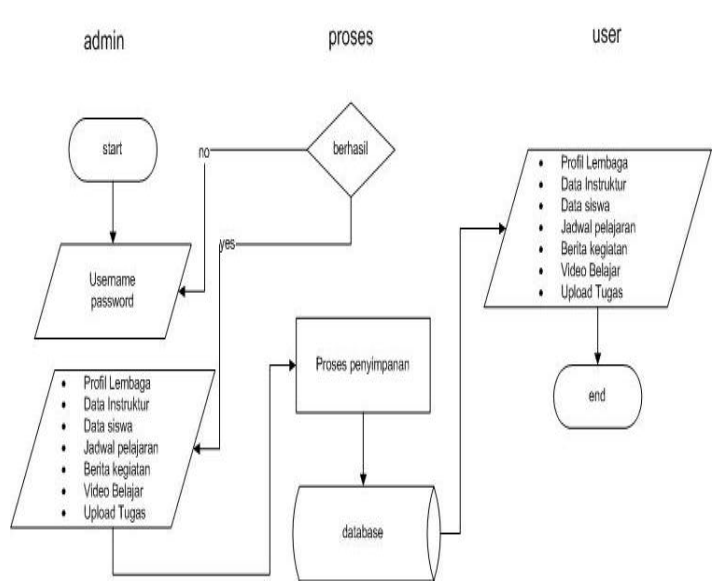

Gambar 2. Flowchart Sistem Yang

Diusulkan

\section{Perancangan Sistem}

Mulyanto (2009) mengemukakan bahwa untuk mendapatkan pengembangan sistem informasi yang berkualitas, diperlukan prosedur-prsedur perancangan sesuai dengan pengembangan system informasi. Perancangan ssistem informasi terdiri dari dua aktivitas utama, yaitu perancanga perangkat keras meliputi perancangan arsitektur serta perancagan perangkat lunak yang meliputi perangkat database yang berupa ERD dan perancangan sistem yang dapat berupa DFD

\section{Perancangan Tabel}

\section{Tabel Admin}

Tabel Admin digunakan untuk menyimpan data - data yang berhubungan dengan Admin. Spesifikasi dari tabel Admin sebagai berikut :

Tabel 1. Admin

\begin{tabular}{|l|c|c|c|c|}
\hline Filed & $\begin{array}{c}\text { Typ } \\
\text { e }\end{array}$ & $\begin{array}{c}\text { Lengt } \\
\text { h }\end{array}$ & $\begin{array}{c}\text { Primar } \\
\text { yKey }\end{array}$ & $\begin{array}{c}\text { AutoIn } \\
\text { creme } \\
\text { nt }\end{array}$ \\
\hline Id_user & Int & 100 & $*$ & $*$ \\
\hline $\begin{array}{l}\text { Usernam } \\
\text { e }\end{array}$ & $\begin{array}{c}\text { Varc } \\
\text { har }\end{array}$ & 100 & & \\
\hline Password & $\begin{array}{c}\text { Varc } \\
\text { har }\end{array}$ & 100 & & \\
\hline Akses & Int & 1 & & \\
\hline
\end{tabular}




\section{Tabel Instruktur}

Tabel Intruktur digunakan untuk menyimpan data yang berhubungan dengan Intruktur. Spesifikasi dari tabel instruktur adalah sebagai berikut:

Tabel 2. Tabel Intruktur

\begin{tabular}{|c|c|c|c|c|}
\hline Nama & Type & Size & $\begin{array}{c}\text { Primar } \\
\text { yKey }\end{array}$ & $\begin{array}{c}\text { Deskrips } \\
\text { i }\end{array}$ \\
\hline Nip & Int & 20 & $*$ & $*$ \\
\hline Nama & $\begin{array}{c}\text { Varcha } \\
\mathrm{r}\end{array}$ & 100 & & \\
\hline Ttl & $\begin{array}{c}\text { Varcha } \\
\mathrm{r}\end{array}$ & 100 & & \\
\hline $\begin{array}{c}\text { Golong } \\
\text { an }\end{array}$ & $\begin{array}{c}\text { Varcha } \\
\mathrm{r}\end{array}$ & 10 & & \\
\hline $\begin{array}{c}\text { Tmt } \\
\text { Varcha } \\
\mathrm{r}\end{array}$ & 10 & & \\
\hline $\begin{array}{c}\text { Jabatan } \\
\text { Varcha } \\
\mathrm{r}\end{array}$ & 50 & & \\
\hline $\begin{array}{c}\text { Pendidi } \\
\text { kan }\end{array}$ & $\begin{array}{c}\text { Varcha } \\
\mathrm{r}\end{array}$ & 100 & & \\
\hline $\begin{array}{c}\text { Tahun } \\
\text { lulus }\end{array}$ & Int & 4 & & \\
\hline
\end{tabular}

\section{Tabel Siswa}

Tabel siswa digunakan untuk menyimpan data yang berhubungan dengan siswa. Spesifikasi dari tabel siswa adalah sebagai berikut:

Tabel 3. Tabel Siswa

\begin{tabular}{|c|c|c|c|c|}
\hline Nama & Type & Size & $\begin{array}{c}\text { PrimaryK } \\
\text { ey }\end{array}$ & $\begin{array}{c}\text { Deskrips } \\
\text { i }\end{array}$ \\
\hline Nis & Int & 4 & $*$ & $*$ \\
\hline Nama & $\begin{array}{c}\text { Varch } \\
\text { ar }\end{array}$ & 100 & & \\
\hline Ttl & $\begin{array}{c}\text { Varch } \\
\text { ar }\end{array}$ & 50 & & \\
\hline $\begin{array}{c}\text { Alama } \\
\text { t }\end{array}$ & $\begin{array}{c}\text { Varch } \\
\text { ar }\end{array}$ & 100 & & \\
\hline $\begin{array}{c}\text { Agama } \\
\text { Varch } \\
\text { ar }\end{array}$ & 50 & & \\
\hline Kelas & $\begin{array}{c}\text { Varch } \\
\text { ar }\end{array}$ & 10 & & \\
\hline
\end{tabular}

\section{Tabel Jadwal}

Tabel jadwal digunakan untuk menyimpan data yang berhubungan dengan jadwal. Spesifikasi dari tabel jadwal adalah sebagai berikut:
Tabel 4. Tabel Jadwal

\begin{tabular}{|l|l|l|c|c|}
\hline Nama & Type & Size & $\begin{array}{c}\text { Primary } \\
\text { Key }\end{array}$ & $\begin{array}{c}\text { Deskrip } \\
\text { si }\end{array}$ \\
\hline Id & Int & 11 & $*$ & $*$ \\
\hline Kelas & Varchar & 100 & & \\
\hline Tahun & Int & 4 & & \\
\hline File & Varchar & 100 & & \\
\hline
\end{tabular}

\section{Diagram Konteks}

Diagram konteks adalah gambaran sistem secara keseluruhan, hanya berisi satu proses yang menggambarkan sistem tersebut terhubung dengan entitas eksternal. Diagram konteks dari Pembelajaran Photoshop Dengan Menggunakan Metode Pembelajaran Pendekatan Web Product Based Learning Di Global Science Institute (GSI) Ternate sebagai berikut:

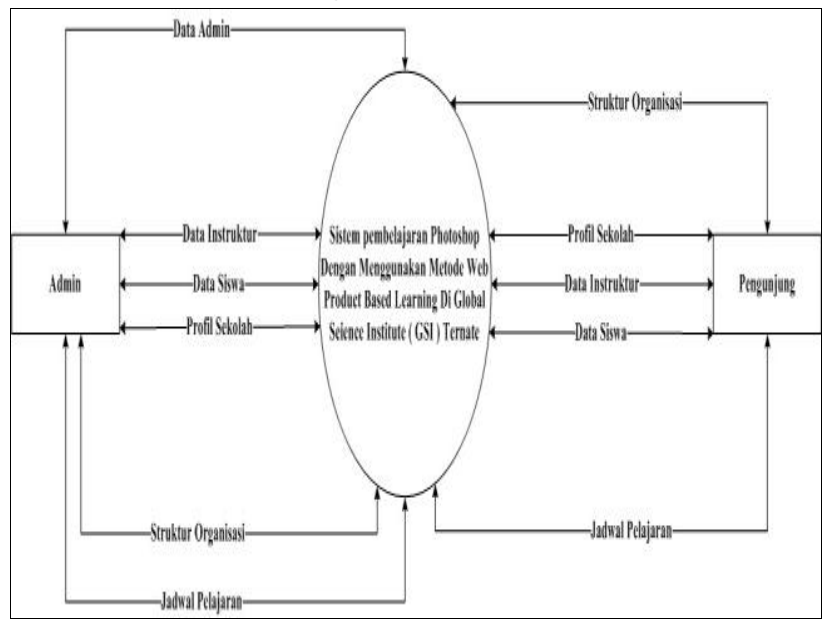

Gambar 3. Diagram Konteks

\section{DFD Level 1}

Diagram Konteks adalah gambaran sistem secara keseluruhan, hanya berisi satu proses yang menggambarkan sistem tersebut terhubung dengan entitas eksternal. Diagram Konteks biasanya disebut Diagram 0, Diagram konteks dari perancangan sistem dapat dilihat pada gambar sebagai berikut: 


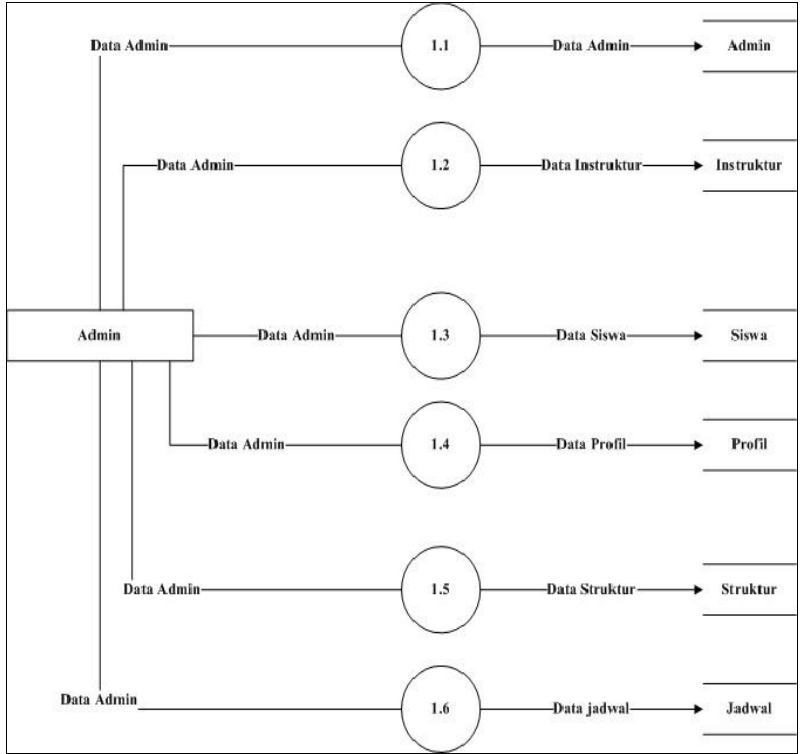

Gambar 4. DFD Level 1

\section{DFD Level 2 (Proses Data Instruktur)}

Diagram konteks adalah gambaran sistem secara keseluruhan, hanya berisi satu proses yang menggambarkan sistem tersebut terhubung dengan entitas eksternal

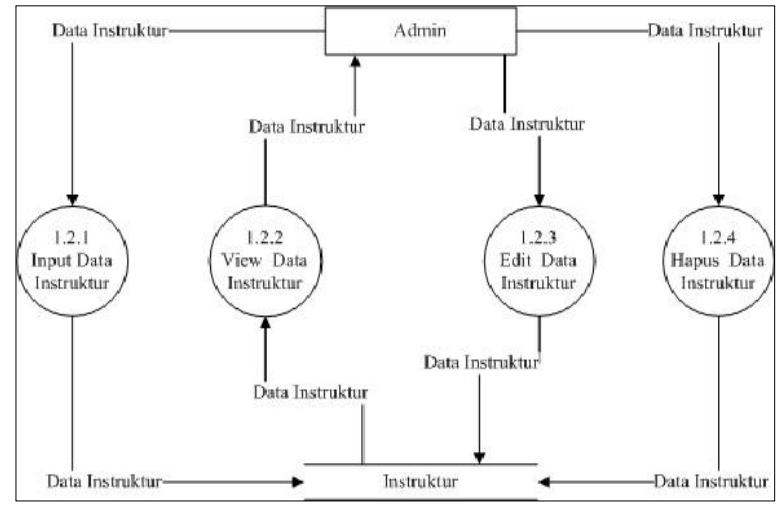

Gambar 5. DFD Level 2 (Proses Data Instruktur)

\section{ERD (Entity Relationship Diagram)}

Entity Relationship Diagram digunakan untuk menggambarkan hubungan yang terjadi pada setiap entitas. ERD dari pembelajaran photoshop dengan menggunakan metode pembelajaran pendekatan web product based learning di global science institute (GSI) ternate ialah sebagai berikut:

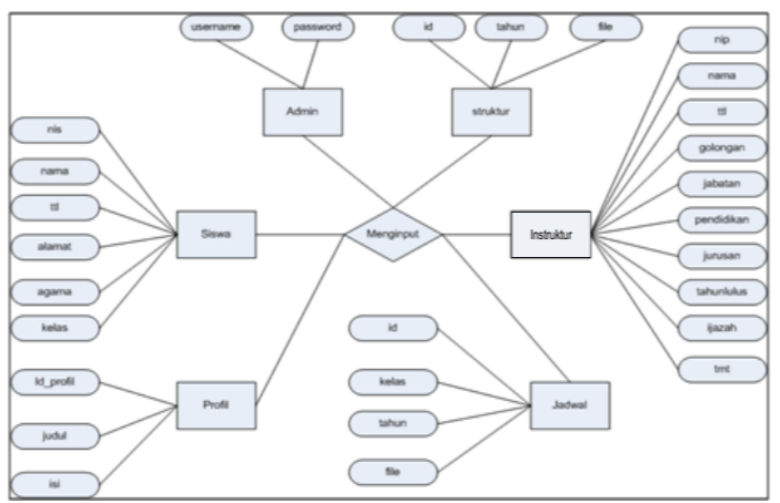

Gambar 6. ERD (Entity Relationship Diagram)

\section{Implementasi Sistem}

Form Implementasi Sistem menunjukan tampilan utama dari sistem yang muncul setelah pengguna berhasil melakukan proses login. Tampilan ini berisi menu-menu utama

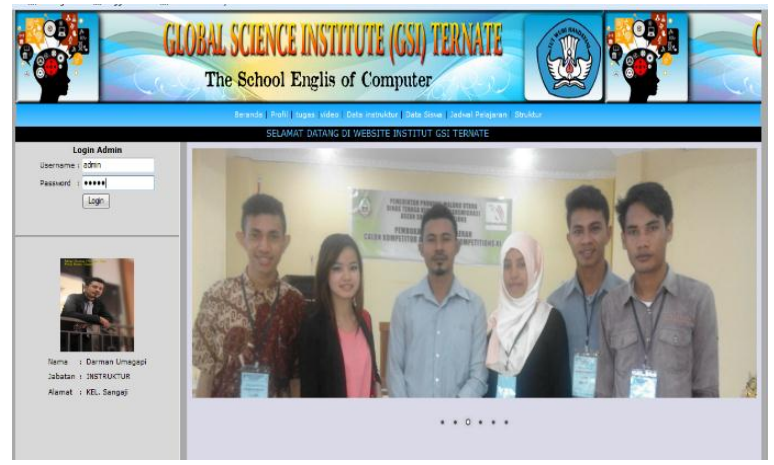

Gambar 7. Halaman Depan Sistem (Beranda)

\section{Halaman Form Input Data Instruktur}

Form Input Data Instruktur merupakan tampilan form untuk menginput data instruktur.

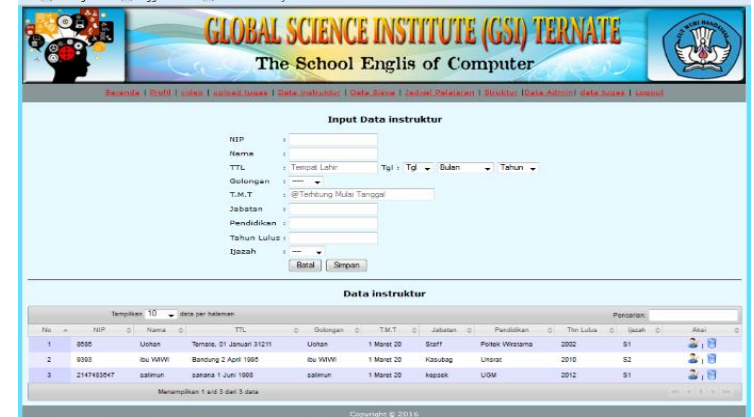

Gambar 8 : Halaman Form Input data Instruktur 


\section{Halaman Form Input Data Siswa}

Form Input Data Siswa merupakan tampilan form untuk menginput data siswa dan di simpan ke database.

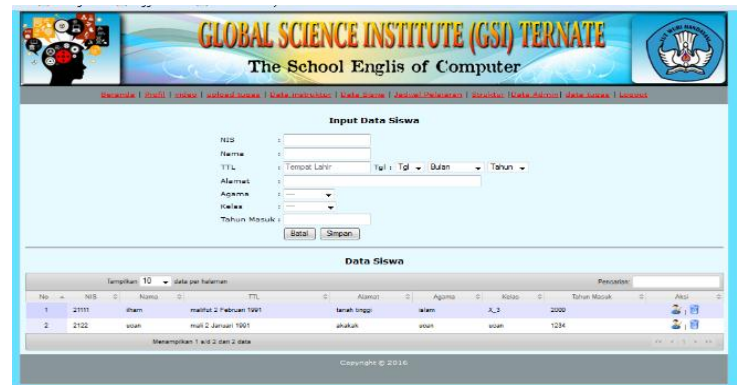

Gambar 9. Halaman form input data siswa

\section{Halaman Form Input Jadwal Pelajaran}

Form Input Jadwal Pelajaran merupakan tampilan form untuk menginput data jadwal pelajaran dan di simpan ke database.

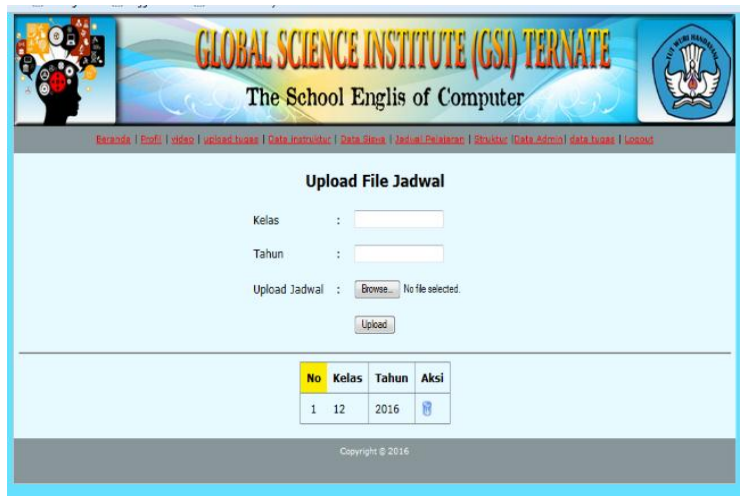

Gambar 10. form input Jadwal Pelajaran

\section{Halaman Form Upload File Video}

Form Upload File Video merupakan tampilan form untuk menginput data video dan di simpan ke database

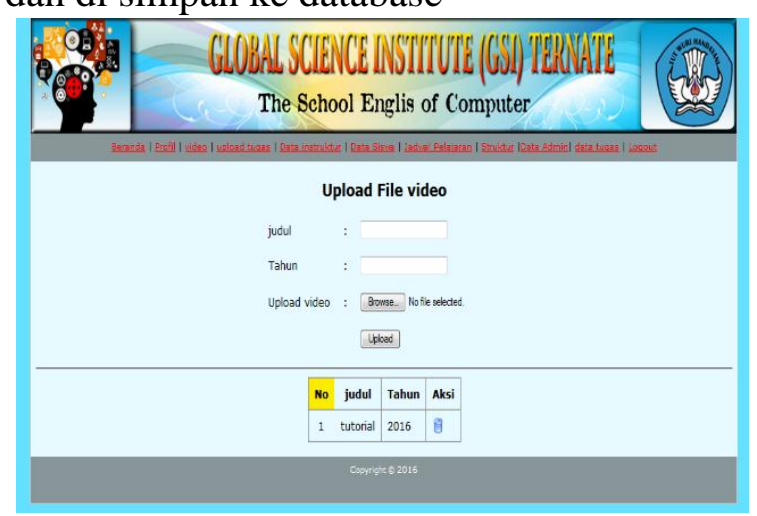

Gambar 11. form Upload File Video

\section{Halaman Form Lihat Video}

Pada gambar di bawah ini merupakan tampilan form untuk siswa melihat video belajara yang sudah di upload oleh instruktur.

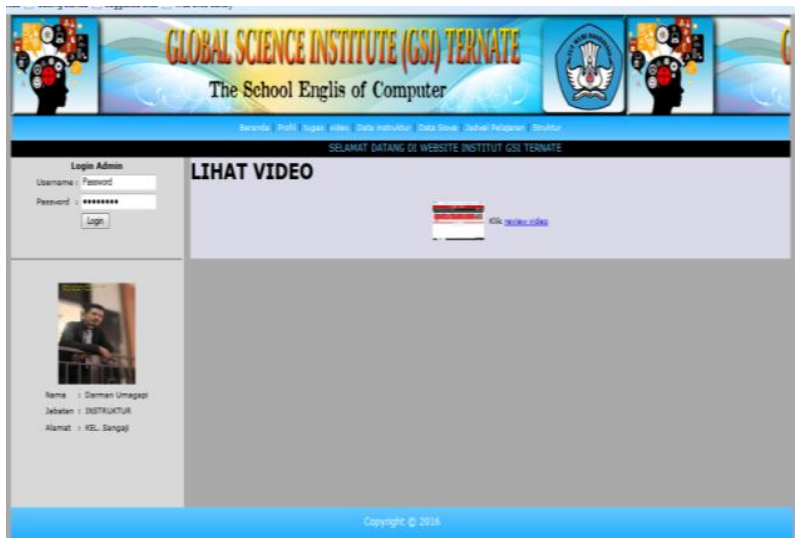

Gambar 12. form Lihat Video

\section{KESIMPULAN}

Dari hasil penelitian ini dapat disimpulkan bahwa Sistem yang dibuat ini akan mempermudah pihak Lembaga terutama seorang instruktur dalam proses belajar mengajar dengan menyajikan video Tutorial yang ada pada website dengan menggunakan Web product Based Learning dan memberikan informasi tentang data siswa kepada pengunjung atau user, dengan sistem ini juga dapat mempermudah pengguna untuk mengetahui informasi tentang Lembaga, instruktur serta data siswa tanpa mengenal jarak dan waktu.

Berdasarkan kesimpulan di atas, maka diajukan saran sebagai berikut : Bagi pihak Global Science Institute (GSI) Ternate dapat menggantikan sistem ini dengan sistem yang lama, karena sistem yang lama masih bersifat manual, sehingga masih membutuhkan waktu yang lama untuk memberikan informasi tentang data siswa, profil lembaga, data instruktur serta metode pembelajaran. Untuk itu di harapkan dengan sistem ini dapat mempermudah instruktur dalam proses belajar mengajar. Dengan begitu siswa 
dapat mengembangkan pengetahuannya melalui sistem based learnig.

\section{DAFTAR PUSTAKA}

Davis, Gordon B. 1991. Konsep dan Penerapan Sistem Informasi. Feni Agustin, Jakarta

Conrad, K. \& TrainingLinks. (2000). Instructional design for web-based training. Amherst: HRD Press.

Moekijat. 2005. Pengantar Sistem Informasi Manajemen. Mandar Maju, Bandung.

HM, Jogiyanto. 2005. Pengenalan Sistem Informasi. AndiOfset, Yogyakarta.

Davidson, G., \& Rasmussen, K.L. (2006). Web-Based Learning: Designing, Implementation, and Evaluation. Upper Saddle River, NJ: Pearson Education, Inc.

Al Fata Hanaf. 2007. Analisis \& Perancangan Sistem Informasi. AndiOfset, Yogyakarta.

Kadir, Abdul. 2008. Tuntunan Praktis Belajar Database Menggunakan $M y S Q L$. AndiOfset, Yogyakarta.

Nugroho, Bunafit. 2008. Latihan Membuat Aplikasi Web PHP dan MySQL dengan Dreamweaver.Gava Media, Yogyakarta.

Mulyanto, Agus. 2009. Sistem Informasi Konsep dan Aplikasi. Pustaka Pelajar, Yogyakarta.

Sugiyono. (2009). Metode Penelitian Bisnis (Pendekatan Kuantitatif, Kualitatif, dan R\&D). Bandung: Alfabeta

Asep Herman S. (2009). Step by Step Web Design theory and Practices. Yogyakarta: Penerbit Andi

Fernandes, Joao PD. (2009). Moodle 1.9 Multimedia. Birmingham Mumbai. Packt Publishing.

Jayan. 2010. CSS Untuk Orang Awam (membangun website tanpa tabel, fleksibel dan \& efektif).Maxikom, Palembang.

Komputer, Wahana. 2010. Panduan Belajar MySQL Database Server. Mediakita, Jakarta.

Darmawan. 2013. Desain dan Pemograman Website. PT Remaja Rosdakarya, Bandung.

Hartono Bambang. 2013. Sistem Informasi Manajemen Berbasis Komputer. Rineka Cipta, Jakarta

Pratama, I. P. E.2014. Sistem Informasi\& Implementasinya. Informatika, Bandung.

Hidayat, TS. 2003. Analisa Dan Perancangan Sistem Pengisian Formulir Rencana Studi Secara Online Di Stimik Perbanas. (Skripsi: Sekolah Tinggi Manajemen Informatika \& Komputer Perbanas, Jakarta)

Boulton, Helen. (2008). Managing eLearning: What are the Real Implications for Schools? Dalam Electronic Journal e-Learning Volume 6 Issue 12008 (11-18) Tersedia pada http://www.ejel.org/ Volume-6/v6-i1/Boulton.pdf. Diakses tanggal 13 maret 2010.

Herman Dwi Surjono. (2008). E-learning UNY. Modul Pelatihan. tersedia pada link http://blog.uny.ac.id/ hermansurjono. Diakses pada tanggal 20 November 2009.

Arisandy Ambarita, Implementasi Sistem E-Learning Menggunakan Software Moodle Pada Polteknik Sains dan Teknologi Wiratama Maluku Utara, IJIS - Indonesian Journal On Information System, Volume 1 Nomor 2 September Tahun 2016 